\title{
EDUCAÇÃO INTEGRAL EM TEMPO INTEGRAL NO BRASIL: algumas lições do passado refletidas no presente
}

\author{
Keila Roberta Cavalheiro Guimarães ${ }^{1}$ \\ Maria de Fátima Matos de Souza 2
}

\section{RESUMO}

O presente artigo tem por objetivo refletir sobre a trajetória histórica das experiências de educação integral em tempo integral, realizadas no Brasil. Partindo da experiência pioneira desenvolvida por Anísio Teixeira, no Centro Educacional Carneiro Ribeiro - BA (1950), o texto evoca diferentes épocas históricas, citando os Ginásios Vocacionais, em São Paulo (1960); a Escola Parque em Brasilia (1960); passando pelo Programa de Formação Integral da Criança - Profic em São Paulo (1980); e pelos Centros Integrados de Educação Pública - Cieps no Rio de Janeiro (1980) e chega ao projeto dos Centros de Atenção Integral à Criança e ao Adolescente (Ciacs), programa este implantado em vários estados brasileiros pelo governo Fernando Collor de Mello (1990). Também incorre na discussão sobre a ampliação do tempo escolar, como possibilidade de melhoria da qualidade do ensino no país. Metodologicamente, utilizamos a pesquisa teórico-bibliográfica. As considerações finais apontam que as experiências materializadas no Brasil, sofreram influências políticas partidárias, que muitas vezes as desconfiguram de seus focos formativos. Os resultados revelam que tais experiências não tiveram fôlego para se consolidarem enquanto política de Estado e se configuram como políticas de governos. Os estudos revelam também, que a partir da década de 90, as políticas educacionais brasileiras passaram a ser conduzidas por orientações de agências internacionais como o Banco Mundial e a UNESCO, no entanto, tais pacotes de reformas não podem ser vistos como melhor alternativa para melhoria da qualidade do ensino, uma vez que outros fatores estão atrelados nessa tarefa.

Palavras-chave: Políticas públicas. Tempo integral/ampliado. Educação integral.

\footnotetext{
1 Mestranda em Educação (PPEB/UFPA). E-mail: keilaguimaraes2008@gmail.com

2 Doutora em Educação (PPEB/UFPA). Professora do Mestrado Acadêmico em Educação (UFOPA/UFPA).E-mail: fmatoz@gmail.com
} 


\title{
FULL-TIME INTEGRAL EDUCATION IN BRAZIL: some lessons from the past reflected in the present
}

\begin{abstract}
The purpose of this article is to reflect on the historical trajectory of the experiences of integral full time education in Brazil. Starting from the pioneering experience developed by Anísio Teixeira, at Carneiro Ribeiro Educational Center - BA (1950), the paper evokes different historical times, citing the Vocational Gymnasiums, in São Paulo (1960); the Park School in Brasilia (1960); through the Integral Child Training Program - Profic in São Paulo (1980); and Cieps in Rio de Janeiro (1980) and comes to the project of Centers for Comprehensive Child and Adolescent Care (Ciacs), a program implemented in several Brazilian states by Fernando Collor de Mello (1990) . It also incurs the discussion about the expansion of school hours as a possibility to improve the quality of education in the country. Methodologically, we use theoretical-bibliographic research. The final considerations point out that the experiences materialized in Brazil suffered political party influences, which often deconfigure them from their training centers. The results reveal that such experiences did not have the strength to consolidate themselves as a State policy and are configured as government policies. The studies also emphasized that, since the 1990s, Brazilian education policies have been guided by guidelines from international agencies such as the World Bank and UNESCO; however, such reform packages cannot be seen as a better alternative for improving the quality of education, once other factors are linked in this task.
\end{abstract}

Keywords: Public policies. Full-time/extended education. Integral education.

\section{EDUCACIÓN INTEGRAL EN TIEMPO COMPLETO EN BRASIL: algunas lecciones}

\author{
del pasado reflejadas en el presente
}

\section{RESUMEN}

El presente artículo tiene por objetivo reflexionar sobre la trayectoria histórica de las experiencias de educación integral a tiempo completo realizadas en Brasil. A partir de la experiencia pionera desarrollada por Anísio Teixeira, en el Centro Educativo Carneiro Ribeiro - BA (1950), el texto evoca diferentes épocas históricas, citando los Gimnasios Vocacionales, en São Paulo (1960); la Escuela Parque en Brasilia (1960); pasando por el Programa de Formación Integral del Niño - Profic en São Paulo (1980); y por los Centros Integrados de Educación Pública - Cieps en Río de Janeiro (1980) hasta el proyecto de los Centros de Atención Integral al Niño y al Adolescente (Ciacs), programa implantado en varios estados brasileños por el gobierno Fernando Collor de Mello (1990). También incurre en la discusión sobre la ampliación del tiempo escolar, como posibilidad de mejora de la calidad de la enseñanza en el país. Metodológicamente, utilizamos la investigación teóricobibliográfica. Las consideraciones finales apuntan que las experiencias materializadas en Brasil, sufrieron influencias políticas partidistas, que muchas veces 
las desconfiguraron de sus focos formativos. Los resultados revelan que tales experiencias no tuvieron aliento para consolidarse como política de Estado y se configuraron como políticas de gobiernos. Los estudios revelan también, que a partir de la década de 1990, las políticas educativas brasileñas pasan a ser influenciadas s por orientaciones de agencias internacionales como el Banco Mundial y la UNESCO, sin embargo, tales paquetes de reformas no pueden ser vistos como mejor alternativa para mejorar la calidad de la enseñanza, ya que otros factores están vinculados en esta tarea.

Palabras clave: Políticas públicas. Tiempo completo. Ampliado y educación integral.

\section{INTRODUÇÃO}

Atualmente observamos no cenário nacional a emergência de políticas públicas destinadas à melhoria da qualidade na educação básica. Para obter este fim, o poder público e a sociedade civil vêm conjugando esforços na tentativa de elevar os indicadores educacionais, como por exemplo, o Índice de Desenvolvimento da Educação Básica (IDEB)³. Dentre as ações, destacamos a ampliação da jornada escolar nas redes públicas de ensino pela implementação de projetos e programas educacionais.

Considerado um tema recorrente, a educação integral em tempo integral sempre esteve presente no Brasil na forma de programas e projetos. Durante alguns momentos de nossa história educacional, ela se fez presente de forma isolada, as experiências do Centro Educacional Carneiro Ribeiro, implantado por Anísio Teixeira, em Salvador- Bahia, na década de 50, dos Ginásios Vocacionais, em São Paulo (década de 1960), dos famosos Centros Integrados de Educação Pública - Cieps, implantados por Darcy Ribeiro, nas décadas de 80 e 90, no estado do Rio de Janeiro, configuram-se como exemplos dessas experiências e servem de referências para diversos estudos no âmbito acadêmico.

De acordo com os estudos de Ribeiro (2017) o discurso justificador para a adoção de Programas e Projetos que visem promover uma educação em tempo integral ancorou-se na ideia da baixa qualidade da educação pública e nas desigualdades socioeducacionais, esperando, desse modo,

\footnotetext{
3 O Índice de Desenvolvimento da Educação Básica (ldeb) foi criado em 2007 e reúne, em um só indicador, os resultados de dois conceitos igualmente importantes para a qualidade da educação: o fluxo escolar e as médias de desempenho nas avaliações.
} 
que essa perspectiva de promover uma educação integral em tempo integral, dentre outras finalidades, pudesse contribuir para diminuir a desigualdade educacional e melhorar os índices de aprendizagem da educação pública brasileira.

\begin{abstract}
A expansão da educação em tempo integral também é objeto de políticas e programas desenvolvidos por diversas unidades federativas e municípios brasileiros. Para muitos, ampliar a jornada escolar e possibilitar às crianças e jovens a exposição às situações de ensino, aprendizagem e desenvolvimento de múltiplas habilidades tem sido considerada medida propulsora de melhor qualidade na aprendizagem e de redução das desigualdades nas oportunidades educacionais (INEP, 2015, p. 98).
\end{abstract}

Foi nesse contexto marcado pelo discurso da melhoria da aprendizagem e de igualdade de condições educacionais e sociais no país, que a educação em tempo integral voltou a ocupar a pauta dos governos, e apesar de já termos tido experiências de políticas públicas educacionais que visavam à promoção de uma educação em tempo integral desde a década de 1950, podemos dizer que a ampliação do tempo (no sentido de extensão da jornada escolar) nas escolas públicas brasileiras, passa a ser efetivamente prevista na legislação brasileira, somente a partir da década de 1990, na Lei de Diretrizes e Bases da Educação Nacional (LDB), Lei 9394/1996, e reafirmada no Plano Nacional de Educação (PNE), Lei 10.172/2001 e no atual Plano Nacional de Educação (PNE - Lei n 13.005/14).

A preocupação com a fundamentação político-pedagógica da ampliação do tempo e das funções da escola tem estado presente na produção bibliográfica sobre o tema e novos aspectos e questões em torno dele vêm surgindo devido ao aparecimento de múltiplas experiências na realidade educacional brasileira (CAVALIERE, 2007).

Segundo Cavaliere (2009) os modelos de organização para realizar a ampliação do tempo de escola que vêm se configurando no País podem ser sintetizados em duas vertentes: uma que tende a investir em mudanças no interior das unidades escolares, de forma que possam oferecer condições compatíveis com a presença de alunos e professores em turno integral, e 
outra que tende a articular instituições e projetos da sociedade que ofereçam atividades aos alunos no turno alternativo às aulas, não necessariamente no espaço escolar, mas, preferencialmente, fora dele.

Diante deste contexto a necessidade de implantação da escola em tempo integral no Brasil tornou-se uma unanimidade, no entanto, seu sentido ainda não está suficientemente estabelecido (CAVALIERE, 2014).

$\mathrm{Na}$ intenção de refletir sobre a trajetória histórica das experiências de escolarização pública em tempo integral no Brasil, trataremos neste estudo da problemática consubstanciada entre a educação em tempo integral/ampliado 4 e a educação integral ${ }^{5}$.

Para tanto, para conduzir este estudo levantamos as seguintes questões (1) Quais as principais experiências de educação integral em tempo integral realizadas no Brasile (2) Como se configura o debate teórico sobre a ampliação do tempo escolar como possibilidade de melhoria da qualidade do ensino no país?

Visando responder as questões acima levantadas, realizamos uma pesquisa teórico-bibliográfica, apoiada nos estudos de Coelho (2007; 2013), Cavaliere (2007; 2009; 2013; 2014), Nunes (2009), Eboli (1983), Boneny (2009), Menezes; Santos (2001), Dib (2010), Gadott (2009), Ribeiro (2017), Torres (2010), Santos (2014) Lima (1996) e outros.

Em termos estruturais, organizamos esse artigo em três momentos. No primeiro momento, apresentamos uma breve discussão sobre as principais experiências de educação integral em tempo integral, realizadas no Brasil. No segundo, tecemos uma discussão acerca da ampliação do tempo escolar na educação básica, como uma possibilidade de melhoria da qualidade do ensino no país, e por último, apresentamos as considerações finais.

\footnotetext{
4 De acordo com a Lei $n^{\circ}$ 11.494/2007, que prevê em seu Art.10 valores diferenciados aos alunos com matrícula em tempo integral, passou a ser considerado "educação básica em tempo integral a jornada escolar com duração igual ou superior a sete horas diárias, durante todo o período letivo, compreendendo o tempo total que um mesmo aluno permanece na escola ou em atividades escolares" (DECRETO No 6.253/2007).

5 Compreendemos a educação integral como a constituição de uma educação para a formação completa do ser humano, o que leva em conta seus aspectos físico, cognitivointelectuais, éticos e estéticos (CAVALIERE, 2007).
} 


\section{EDUCAÇÃO INTEGRAL EM TEMPO INTEGRAL: algumas experiências brasileiras}

As temáticas "educação integral" e "tempo integral" são temáticas que vêm se destacando no atual cenário político-educacional. Dentro deste debate, algumas propostas de educação foram desenvolvidas visando melhorar a qualidade do ensino no país, a literatura sobre o assunto nos mostra que desde a década de 1950 tivemos no Brasil, algumas experiências emblemáticas de implantação de propostas na educação básica que tinham como uma de suas finalidades, promover uma educação integral em tempo integral, conforme podemos verificar no Quadro 1.

Quadro 1 - Experiências pioneiras e históricas de implantação da escolarização de educação em tempo integral no Brasil - (Período de 1950 1990) Século XX

\begin{tabular}{|c|c|c|c|}
\hline Experiência & Década & Local & Breve descrição da Experiência \\
\hline $\begin{array}{c}\text { Centro } \\
\text { Educacional } \\
\text { Carneiro } \\
\text { Ribeiro (CECR) }\end{array}$ & 1950 & $\begin{array}{l}\text { Salvador } \\
\text { (BA) }\end{array}$ & $\begin{array}{l}\text { Concebido por Anísio Teixeira, o primeiro } \\
\text { centro de educação popular do Brasil foi } \\
\text { criado por um governo estadual e contou } \\
\text { com o apoio do governo federal, por meio } \\
\text { do Centro Regional de Pesquisas } \\
\text { Educacionais da Bahia, vinculado ao Instituto } \\
\text { Nacional de Estudos Pedagógicos (Inep). O } \\
\text { CECR teve seu funcionamento de } 1950 \text { a } \\
1969 \text {, com dezenove anos de duração } \\
\text { (NUNES, 2009). }\end{array}$ \\
\hline $\begin{array}{c}\text { Ginásios } \\
\text { Vocacionais } \\
\text { (GV) }\end{array}$ & 1960 & $\begin{array}{l}\text { Estado de } \\
\text { São Paulo }\end{array}$ & $\begin{array}{l}\text { Os Ginásios Vocacionais foram um projeto } \\
\text { educacional experimental que existiu entre } \\
1961 \text { e } 1970 \text { e totalizaram seis unidades } \\
\text { escolares que, além de São Paulo, } \\
\text { contemplaram as cidades de Batatais, } \\
\text { Americana, Barretos, Rio Claro e São } \\
\text { Caetano. } \\
\text { Após uma intervenção militar ocorrida em } \\
1969, \text { foram formalmente extintos em } 1970 . \\
\text { Um dos argumentos utilizados para extingui- } \\
\text { los foi o de que era um projeto caro, elitista e } \\
\text { inviável de ser expandido para a rede de } \\
\text { ensino como um todo (CHIOZZINI e SANTOS, } \\
2017, \text { p.2-3). }\end{array}$ \\
\hline $\begin{array}{c}\text { Escolar Parque } \\
\text { de Brasília }\end{array}$ & 1960 & $\begin{array}{l}\text { Brasília } \\
\text { (DF) }\end{array}$ & $\begin{array}{l}\text { Inspirada na experiência pioneira do CECR, a } \\
\text { Escola Parque de Brasília, abrangendo o } \\
\text { período inicial de seu funcionamento, que se } \\
\text { situa entre } 1960 \text { e } 1964 \text {. } \\
\text { O caráter inovador da proposta implicava } \\
\text { mudanças significativas da instituição } \\
\text { escolar. Sob a influência das ideias } \\
\text { pragmatistas de Dewey, a nova escola era } \\
\text { uma comunidade socialmente integrada, de }\end{array}$ \\
\hline
\end{tabular}




\begin{tabular}{|c|c|c|c|}
\hline & & & $\begin{array}{l}\text { modo a proporcionar uma real experiência } \\
\text { de vida. }\end{array}$ \\
\hline $\begin{array}{l}\text { Programa de } \\
\text { Formação } \\
\text { Integral da } \\
\text { Criança } \\
\text { (PROFIC) }\end{array}$ & 1980 & $\begin{array}{l}\text { Estado de } \\
\text { São Paulo }\end{array}$ & $\begin{array}{l}\text { Foi uma política pública que foi } \\
\text { implementada em São Paulo, entre os anos } \\
\text { de } 1986 \text { e 1993. Este programa público, } \\
\text { chamado Profic - Programa de Formação } \\
\text { Integral da Criança -, procurou estender o } \\
\text { tempo de permanência das crianças pobres } \\
\text { na escola e expandir as condições para seu } \\
\text { melhor desempenho na aprendizagem. } \\
\text { O Profic foi idealizado como um projeto de } \\
\text { Governo, envolvendo mais de uma } \\
\text { Secretaria de Estado (Saúde, Promoção } \\
\text { Social, Trabalho, Cultura, Esportes e Turismo), } \\
\text { o que o diferenciou - como concepção e } \\
\text { não como realização - de projetos } \\
\text { precedentes ou contemporâneos (GIOVANNI } \\
\text { E SOUZA, 1999). }\end{array}$ \\
\hline $\begin{array}{c}\text { Centros } \\
\text { Integrados } \\
\text { De Educação } \\
\text { Pública } \\
\text { (CIEPs) }\end{array}$ & $1980 / 1990$ & $\begin{array}{l}\text { Estado do } \\
\text { Rio de } \\
\text { Janeiro }\end{array}$ & $\begin{array}{l}\text { Instituições idealizadas no Brasil para a } \\
\text { experiência de escolarização em tempo } \\
\text { integral, voltadas para as crianças das } \\
\text { classes populares, tentando atender as suas } \\
\text { necessidades e interesses. } \\
\text { Os CIEPs foram criados na década de } 80 \text { por } \\
\text { Darcy Ribeiro, quando era Secretário da } \\
\text { Educação no Rio de Janeiro, no governo de } \\
\text { Leonel Brizola. O objetivo era proporcionar } \\
\text { educação, esportes, assistência médica, } \\
\text { alimentos e atividades culturais variadas, em } \\
\text { instituições colocadas fora da rede } \\
\text { educacional regular. Além disso, estas } \\
\text { escolas deveriam obedecer a um projeto } \\
\text { arquitetônico uniforme. }\end{array}$ \\
\hline $\begin{array}{c}\text { Centros } \\
\text { Integrados de } \\
\text { Apoio à } \\
\text { Criança } \\
\text { (CIACs) }\end{array}$ & 1990 & Nacional & $\begin{array}{l}\text { O projeto CIAC foi criado a partir de 1990, no } \\
\text { governo do presidente Fernando Collor de } \\
\text { Mello (1990-1992) como parte das políticas } \\
\text { sociais de seu governo. } \\
\text { Segundo Dib (2010, p.64) Este novo } \\
\text { programa, combina características do } \\
\text { PROFIC e dos CIEPs e tem como temática a } \\
\text { educação integral, no entanto, não mais } \\
\text { restrita ao Estado do Rio de Janeiro ou São } \\
\text { Paulo, mas em nível da União, sob o } \\
\text { patrocínio da Legião Brasileira de Assistência, } \\
\text { Ministério da Saúde e Ministério da Criança. } \\
\text { Nessa escola, as crianças permaneciam } \\
\text { durante oito horas por dia, estudando, } \\
\text { jogando e aprendendo. Além de três } \\
\text { refeições oferecidas por dia, os alunos } \\
\text { receberiam assistência médica, dentária e } \\
\text { educação sobre higiene básica. }\end{array}$ \\
\hline
\end{tabular}

Fonte: Quadro elaborado pela autora (2017).

Conforme podemos verificar no quadro 1, o processo de implantação de experiências de educação que tinha como um de seus propósitos 
promover uma educação integral em tempo integral é fruto de uma demanda histórica no Brasil. O acúmulo dessas experiências, mesmo que descontínuas, realizadas em diversos contextos do país, nos permite compreender que a efetivação de tal política demanda às redes escolares, repensar formas de organização e distribuição de recursos tais como: financeiros, espaciais, humanos etc. Neste contexto de redimensionamento do próprio papel da escola pública, a questão da qualidade parece emergir como elemento da democratização do saber. Não basta colocar todos na escola, mas sim discutir e procurar formas qualitativas de atender ao processo de escolarização das crianças e adolescentes.

Com o propósito na investigação e descrição de algumas experiências tendo em vista o momento histórico que as gerou, as principais características e aspectos educacionais. Apresentamos as experiências relacionadas à educação integral com vista à ampliação do tempo escolar, ocorridas no Brasil, seguindo a ordem cronológica de criação das mesmas:

\subsection{Centro Educacional Carneiro Ribeiro - Bahia (1950-1969)}

O primeiro Centro de Educação Popular foi criado por um governo estadual da Bahia que contou com o apoio do governo federal, por meio do Centro Regional de Pesquisa Educacional da Bahia, vinculado ao Instituto Nacional de Pesquisas Educacionais (INEP). O Centro de Educação Popular foi nomeado pelo governador da época, "Octávio Mangabeira, de Centro Educacional Carneiro Ribeiro, em homenagem ao educador baiano que se distinguira na formação de intelectuais brasileiros prestigiados como Ruy Barbosa e Euclides da Cunha" (NUNES, 2009, p.123).

De acordo com Nunes (2009) o Centro Educacional tinha a capacidade de receber quatro mil alunos aproximadamente. Para cada 20 alunos havia um profissional habilitado. Os professores foram todos recrutados na capital baiana e no interior do estado. Passaram por cursos de aperfeiçoamento no Centro Regional de Pesquisas Educacionais da Bahia, no Curso de Artes Industriais do SENAI, no Rio de Janeiro, na Divisão de Aperfeiçoamento do Magistério do Centro Regional de Pesquisas 
Educacionais de Belo Horizonte, e alguns receberam bolsas para estudar nos Estados Unidos da América do Norte.

A respeito dessa proposta de educação, foi desenhado um projeto arquitetônico para abrigar as atividades pensadas para esse projeto de educação integral e de atendimento em tempo integral.

O projeto de construção do Centro comportava quatro escolasclasse de nível primário para mil alunos cada, com funcionamento em dois turnos; uma escola parque, com sete pavilhões destinados às práticas educativas, onde os alunos completavam sua educação no turno alternado ao da classe. Aos alunos do centro era oferecido um dia completo de permanência em ambientes educativos. Havia, ainda, um plano de manter, numa residência apropriada, $5 \%$ dos meninos, sem lar, mas essa residência nunca foi construída. A construção dessas instalações físicas foi dada como encerrada em 1964 (NUNES, 2009, p. 126).

Terezinha Eboli (1983) descreve em seu livro "Uma experiência de educação integral" que a Escola-Classe era um conjunto de 12 salas, planejadas para o funcionamento da melhor forma possível para ensino de letras e ciências, com áreas cobertas, com gabinetes médico e dentário, dependências para administração, jardim, horta e áreas livres. Era uma escola parcial, nela os alunos permaneciam por quatro horas aprendendo Linguagem, Aritmética, Ciências e Estudos Sociais. Após o horário da EscolaClasse, os alunos encaminhavam-se para a Escola-Parque (e aqueles que passavam a manhã nesta, dirigiam-se para a Escola-Classe), onde permaneciam por mais quatro horas, para completar seu tempo integral de educação com as atividades dos diversos setores.

Segundo Nunes (2009) na Escola-Parque os alunos não eram agrupados só pela idade, mas, sobretudo, pelas suas preferências, em turmas de 20 a 30 no máximo, pelos diversos setores, todos em funcionamento, para realizar inúmeras atividades tais como:

- Artes aplicadas (desenho, modelagem e cerâmica, escultura em madeira, cartonagem e encadernação, metal, couro, alfaiataria, bordados, bijuterias, tapeçaria, confecção de brinquedos flexíveis, tecelagem, cestaria, flores) no Setor de Trabalho; _ Jogos, recreação e ginástica no Setor de Educação Física e Recreação; _Grêmio, jornal, rádio-escola, banco e loja no Setor Socializante; _ Música 
instrumental, canto, dança e teatro no Setor Artístico; _ Leitura, estudo e pesquisas no setor de Extensão Cultural e Biblioteca (NUNES, 2009, p.126).

Na Escola-Parque concentrava-se a direção e administração geral, o setor de Currículo, Supervisão e Orientação Educativa, a assistência médicoodontológica e refeitórios para alimentar os alunos.

O Centro educacional Carneiro Ribeiro trazia em sua origem a ideia de que a escola deve valorizar as atividades e as práticas do cotidiano, ligando a educação à vida.

Para Coelho (2007) as atividades educativas que consubstanciam uma educação integral na visão de Anísio Teixeira, não estavam dissociadas de um tempo integral na instituição formal de ensino, mas eram realizadas no que hoje denominamos de contraturno, ou seja, havia uma clara distinção entre as atividades ditas escolares - que aconteciam nas Escolas-Classe, em um turno - e as atividades diversificadas - que ocorriam na escola-parque, no turno contrário ao anterior.

Coelho ressalta ainda, que essa diferenciação aponta para uma dissociação entre o que se denomina atividades escolares e outras atividades que poderiam, inclusive, ser entendidas e avaliadas como mais prazerosas, diferentes daquelas realizadas nas escolas-classe. E caracteriza, em sua visão, como uma concepção de educação integral em que a formação completa não é vista integradamente.

\subsection{Ginásios Vocacionais - São Paulo (1962- 1969)}

Na década de 1960 tivemos outra experiência de educação integral com atendimento em tempo integral, trata-se dos Ginásios Vocacionais, implantado em São Paulo. Os Ginásios Vocacionais duraram 8 anos, de 1962 a 1969, foram extintos pela ditadura militar, sendo que ao longo do período foram implantadas seis unidades, estando uma na capital (São Paulo), e as outras cinco eram situadas em cidades do Interior: Americana, Batatais, Rio Claro, Barretos e São Caetano do Sul. 
Conforme os estudos de Tamberlini (2001) o Ginásios Vocacionais tiveram a sua criação precedida de uma pesquisa de comunidade. As cidades escolhidas apresentavam características diversas, por exemplo, São Paulo, mais cosmopolita, Americana, industrial, Batatais, uma região agrícola, e assim, sucessivamente. Segundo a autora essa proposta de educação era efetivada como resultante do ambiente total, era extremamente rica que se construiu com uma visão da totalidade do processo educacional, partia de uma pesquisa de comunidade para elaborar um currículo amplo, integrado, com uma metodologia diferenciada e com a preocupação de propiciar o desenvolvimento do educando em todos os seus aspectos, envolvendo o raciocínio, a memória, a emoção e a imaginação, como afirma Tamberlini (2001, p.11).

\begin{abstract}
Esta pedagogia que visava a promoção do ser humano, oferecendo uma formação que englobava um desenvolvimento pleno, se ancorava em uma visão de mundo e compreendia a complexidade da tarefa educativa que, para se realizar, deveria se valer da contribuição de outros campos do conhecimento, cuja importância já era bastante considerada na época, tais como a psicologia, a sociologia, a biologia, etc.[...] ○ Ensino Vocacional tinha uma visão de saber plural, visando educar o aluno integralmente, dando-lhe mais do que instrução, uma formação. Os métodos ativos, associados ao exercício da pesquisa, análise e síntese, valorizando simultaneamente ação e pensamento, contribuíam para que se forjasse uma concepção de história - as discussões acerca dos fatos pertinentes que ocorriam no presente permitiam que se dotasse 0 passado de significado - que conduziria a uma compreensão profunda da transformação da sociedade, acentuando a dimensão política dominante nesta proposta.
\end{abstract}

Tamberlini (2001) afirma que os idealizadores da proposta pedagógica dos Ginásio Vocacionais acreditavam que os aspectos econômicos, sociais, políticos, artísticos, religiosos são manifestações de uma mesma realidade cultural, interdependentes entre si. Deste modo, O trabalho integrado visava à elaboração de novos conhecimentos, à compreensão da complexidade do mundo, à ideia de que somos capazes de modificar a realidade, tornando-nos agentes históricos e culturais. A autora esclarece ainda, que nessas escolas a concepção de formação integral que também se valia das contribuições da psicologia e outras disciplinas, na verdade, se concretizava 
em um trabalho integrado que promovia simultaneamente 0 desenvolvimento cognitivo e afetivo do alunado, respeitando, inclusive, suas diversidades individuais, culturais, sociais, etc.

Conforme Tamberlini (2001) a proposta dos Ginásios Vocacionais foi uma experiência ímpar, com características peculiares, baseada em uma proposta de educação que adotava a democracia como prática pedagógica, havia baixo índice de reprovação e evasão, com forte participação da comunidade nas decisões gerais. Defendia-se nesta experiência a relação entre teoria e prática, a busca da formação integral do indivíduo e formas de avaliação diferenciadas, entre outras características diferenciadoras e inovadoras.

\subsection{Escola Parque - Brasília (1960-1964)}

Na década de 1960, também merece destaque a experiências de escolarização em tempo integral da Escola Parque de Brasília, implantada em 1960, ano de inauguração da cidade de Brasília. A proposta inovadora naquela época implicava mudanças significativas da instituição escolar. De acordo com os estudos de Pereira e Rocha (2011) essa experiência de educação sofreu influências das ideias pragmatistas de Dewey, essa escola era uma comunidade socialmente integrada, possibilitando uma real experiência de vida.

Esse modelo de escola resgatava a ideias de educação integral, nos moldes do Centro Educacional Carneiro Ribeiro, popularmente conhecido como Escola Parque da Bahia, no entanto, existiu uma grande diferença entre essas duas propostas, pois na Escola Parque de Brasília, a composição social do alunado era basicamente, de classe média alta, com um número muito pequeno de crianças provenientes das classes populares, já na escola Parque da Bahia, a composição social do alunado era especialmente para as classes populares.

Conforme Pereira e Rocha (2011) a Escola Parque de Brasília, estava localizada num local privilegiado, uma quadra do Plano Piloto, onde residiam famílias de nível social elevado: deputados, senadores, altos 
funcionários da burocracia estatal, executivos, cujos filhos eram alunos da instituição. Segundo as autoras, a parcela insignificante de filhos de operários que tinha acesso à Escola Parque provinha dos acampamentos instalados nas quadras, que estavam em construção, o que configurava uma permanência transitória desses alunos na referida escola. Esse fato, expressa radicalmente a diferença da Escola Parque de Salvador, organizada para atender a população de baixa renda. No caso de Brasília, a escola pública, que deveria ser modelo para o país como uma escola realmente democrática, aberta a todas as classes sociais, circunstancialmente desfigurou-se, voltando-se para a elite.

Em termos semelhantes, se comparada à experiência da Escola Parque da Bahia, podemos destacar a jornada escolar de tempo integral, na qual os alunos permaneciam um período completo de oito horas. Pois assim, como na Escola Parque da Bahia, os alunos que frequentavam pela manhã a Escola Classe à tarde iam para a Escola Parque e vice-versa.

$\mathrm{Na}$ Escola Classe, os alunos eram distribuídos nas salas de aulas, de acordo com o grau de escolaridade, já na Escola Parque, os alunos eram agrupados de acordo com a idade e o tipo de aptidões, pautadas em práticas educativas diversificadas, no campo do trabalho das artes, de educação física e da biblioteca, etc. Portanto, a convivência dos alunos dava-se com seu grupo da Escola Classe, quanto com o grupo da Escola Parque.

\subsection{Programa de Formação Integral da Criança (Profic) - São Paulo (1986- 1993)}

Dando um salto na linha do tempo, destacamos a experiência do Programa de Formação Integral da Criança (PROFIC), implantado em São Paulo, entre os anos de 1986 e 1993. Essa proposta de escola foi rejeitada inicialmente pela rede estadual de ensino, e apresentou dificuldade em sua implementação. A literatura especializada sobre o assunto revela que, o Programa mesmo com seu segundo ano de existência, nunca foi considerado como uma atividade substantiva nas ações da Secretaria de Educação do Estado de São Paulo, visto que suas características próprias 
formais de execução, em que cada unidade do Programa acabou por adquirir um modo particular de atuação, contribuíram para descaracterizar a cultura vigente na Secretaria de Educação de homogeneização das atividades no interior da Rede de Ensino de São Paulo.

De acordo com os estudos de Giovani e Souza (1999) a experiência do Programa Profic, configura-se como a primeira experiência em educação integral que se utilizou da parceria como uma estratégia explícita e deliberada para o aproveitamento de recursos preexistentes. Principalmente nos primeiros anos de vigência do programa, a cooperação com as Prefeituras Municipais e com as entidades assistenciais foi decisiva. Diferente de outras experiências experimentadas no Brasil, tais como: a do Centro Educacional Carneiro Ribeiro no estado da Bahia (1950); os Ginásios Vocacionais, em São Paulo (1960), Os Cieps no Rio de Janeiro (1980/90), os Ciacs (1990) implantado pelo programa Federal em vários estados brasileiros, - Profic buscou parcerias no chamado terceiro setor e no nível mais descentralizado do poder público: o município.

É importante ressaltar que, o Profic foi idealizado como um projeto de Governo, que envolvia mais de uma Secretaria de Estado (Saúde, Promoção Social, Trabalho, Cultura, Esportes e Turismo), "o que o diferenciou - como concepção e não como realização - de projetos precedentes ou contemporâneos" (GIOVANI; SOUZA, 1999, p.72).

A proposta do Profic era vista na concepção corrente como a instituição que tinha a finalidade de socialização daquela parcela do saber sistematizado que constitui o indispensável à formação e exercício da cidadania: a classe menos favorecida, esse programa se propunha ir além da função de instrução, agregando a proteção como uma missão institucional paralela.

Segundo Ferretti (1991) o Profic atribui à concepção deste Programa pautada em duas vertentes: de um lado, estaria identificada uma aproximação mais que casual, com programas voltados para a área da saúde, como os de Medicina Comunitária e de Atenção Primária à Saúde; 
de outro lado, a vertente seria o conjunto de teorias de comunidades oriundas da sociologia funcionalista norte-americana.

O processo de implementação, por meio de grandes resistências e, ao mesmo tempo, as difíceis adesões, revelou que o custo de implantação de programas diferenciados dos padrões convencionais de instituições complexas e altamente burocratizadas é muito alto. Esse Programa não contou com boa estratégia para romper as resistências e conquistar a burocracia. As resistências estruturais aliadas às conjunturas políticas específicas foram empecilhos muito fortes para a implantação do Profic. Por outro lado, a busca de estruturas alternativas para a implantação do programa, tais como as parcerias com prefeituras e entidades assistenciais revelou-se de grande legitimidade na implementação, uma vez que possibilitou a utilização direcionada de demandas preexistentes, bem como de mecanismos políticos tradicionais.

2.5 Centros Integrados de Educação Pública (Cieps) - Rio de Janeiro (1983 1987 e 1991 - 1994)

Outra política pública que foi implementada na década de 1980 foi a criação dos Centros Integrados de Educação Pública, conhecidos como CIEPs. Idealizado pelo sociólogo Darcy Ribeiro, protagonista do Programa Especial de Educação (PEE), durante os dois governos de Leonel Brizola no estado do Rio de Janeiro. Darcy Ribeiro foi influenciado pelas ideias de Anísio Teixeira e acreditava que a escola brasileira ainda não podia ser chamada de pública por ser seletiva e elitista.

Darcy Ribeiro valeu-se várias vezes de sua argumentação sociológica para sustentar a defesa da escola em tempo integral como eixo de uma experiência política mais justa, democrática e humanizadora.

Reconhecendo claramente as dificuldades do Brasil em incorporar nos setores populares a agenda pública de benefícios sociais, Darcy Ribeiro colocou na escola pública de tempo integral a expectativa positiva de modificar a tradição elitista e ampliar o alcance ao acesso e permanência 
de um número mais expressivo possível de alunos na experiência dessa escola.

Quando Darcy Ribeiro defende o Programa Especial na década de 80, ele também o faz como uma recuperação, interrompida pela violência do golpe de 64. Os Cieps vieram no desmonte do autoritarismo no Brasil. Eram fruto, portanto, da redemocratização. Darcy Ribeiro pretendia recolocar com o Programa Especial de Educação a prioridade que havia sido subtraída no regime militar.

Segundo Bomeny (2009) o sonho de Darcy Ribeiro, era que o Ciep fosse atrativo para a classe média, tinha que ser tão bom que os filhos da classe média tivessem que disputar uma vaga na escola. Por certo, a ênfase dada em todos os discursos, na prioridade para o programa das classes populares e da população da periferia, criou um vínculo simbólico entre clientela pobre e clientela dos Cieps.

Outro ponto que nos chama a atenção na proposta dos Cieps, foi a forma como foram organizadas suas atividades educativas, pois, na proposta pedagógica do Centro educacional Carneiro Ribeiro, idealizada por Anísio Teixeira, o tempo escolar era dividido entre as Escolas-Classe e Escolas-Parque, para agregar as atividades que compunham sua concepção de formação completa. Já Darcy Ribeiro, nos Cieps, procurou congregá-las todas no mesmo espaço, e com isso, promover uma maior integração entre as atividades educativas desenvolvidas pela escola, bem como possibilitar entendê-las, todas como componentes curriculares inerentes a essa formação do aluno nesse espaço de formação.

A proposta dos Cieps tinha como objetivo proporcionar educação, esportes, assistência médica, alimentação e atividades culturais variadas. Além disso, essas escolas deveriam obedecer a um projeto arquitetônico uniforme. A ideia dos Cieps considerava que todas as unidades deveriam funcionar de acordo com um projeto pedagógico único e com uma organização escolar padronizada, com o intuito de evitar a diferença de qualidade entre as escolas. No entanto, o projeto dos Cieps recebeu várias críticas, entre elas, as referentes ao custo dos prédios, a qualidade de sua 
arquitetura, sua localização e sobre sua jornada escolar para o regime de oito horas.

Os CIEPs ainda existem com este nome, mas, no governo de Fernando Collor de Melo, novas unidades passaram a se chamar CIACs (Centros Integrados de Atendimento à Criança). A partir de 1992, estes últimos passaram a ter novo nome - CAICs (Centros de Atenção Integral à Criança). Ao todo, foram construídos cerca de 500 CIEPs e 400 CIACs (MENEZES E SANTOS, 2001).

\subsection{Centros Integrados de Apoio à Criança (CIACs)}

Na década de 1990, o governo de Fernando Collor de Mello edificou como projeto de escola pública em tempo integral os chamados CIACs, programa federal implantado em vários estados brasileiros. Os CIACs foram instituídos em 1991 como parte do "Projeto Minha Gente", inspirados no modelo dos Centros Integrados de Educação Pública (CIEPs), do Rio de Janeiro, implantados na gestão de Leonel Brizola. O objetivo era prover a atenção à criança e ao adolescente, envolvendo a educação fundamental em tempo integral, programas de assistência à saúde, lazer e iniciação ao trabalho, entre outros (MENEZES; SANTOS, 2001).

Em decorrência do impeachment sofrido pelo presidente Collor, causando sua saída, o projeto é assumido pelo vice-presidente da República, Itamar Franco (1992), que passa tal incumbência ao Ministério da Educação. A partir de então, o projeto sofreu uma reformulação e passou a ser denominado de Programa Nacional de Atenção Integral à Criança e ao Adolescente - PRONAICA - que buscava articular-se com órgãos federais, estaduais, ONG's e organismos internacionais para o desenvolvimento de ações de atenção integral à criança e ao adolescente. Desta forma, os CIACs passaram a ser denominados CAICs - Centro de Atenção Integral à Criança (DIB, 2010).

O programa ao se tornar CAICs, tomou como base inicial para a implementação de sua estratégia, a noção de que o CAICs não era escola, porém um centro voltado para a prestação de todos os serviços essenciais 
ao pleno desenvolvimento da infância e juventude. E de que as crianças e os adolescentes deveriam considerar-se o centro de tudo, fazendo convergir para eles, de forma integrada, oportuna e eficientemente estruturada, os serviços sociais necessários a sua formação como afirma (DIB, 2010, p. 66).

\begin{abstract}
Ao manter as crianças envolvidas o dia todo nos CAIC's, o projeto tinha dois objetivos: oferecer àquelas famílias marginalizadas pela estrutura econômica, condições mínimas para que seus filhos frequentassem a escola, onde Ihes era oferecido o que a sua família não teria condições de proporcionar: comida, vestuário (uniforme), assistência médico-odontológica, etc. e evitar que essas crianças se lançassem precocemente no mercado de trabalho (sub-empregos). Os dois objetivos unificaram-se na tentativa de diminuir o índice de evasão e repetência escolar, sem, no entanto, considerarem os motivos que realmente levavam essas famílias a se tornarem marginalizadas pela sociedade.
\end{abstract}

Em janeiro de 1995, o Presidente Fernando Henrique Cardoso (19952002) extinguiu a Secretaria Especial do Ministério da Educação que gerenciava a implementação dos CIAC's nas unidades federativas, passando esta responsabilidade aos domínios dos governos estaduais e municipais. A literatura disponível sobre o assunto aponta que a maioria desses governos não preservou a proposta inicial, apenas aproveitou a estrutura física para manter alunos no sistema convencional de educação.

De acordo com os estudos de Freitas e Galtier (2007), tanto o projeto dos CAICs, quanto o projeto do Cieps implantado no Rio de Janeiro na década de 80 , foram projetos que contribuíram para a realização em grande escala de um projeto que para muitos era visto como impossível, apesar dos problemas e limites.

Ao historiar brevemente sobre o contexto dos diversos projetos educacionais implementados no Brasil, a partir da década de 1950, e que recorreram à ampliação do tempo escolar, podemos apontar que além da materialização dos referidos projetos terem se apresentado em diferentes maneiras, muitas dessas experiências não atingiram plenamente seus objetivos. No entanto, tais experiências de educação têm em comum "tanto uma dimensão quantitativa (mais tempo na escola e no seu entorno), 
quanto uma dimensão qualitativa (a formação integral do ser humano). Essas duas dimensões são inseparáveis" (GADOTTI, 2009, p. 33).

Compreendemos que fatores como a instabilidade política, a insuficiência de mecanismos de fiscalização, prática da democracia, avaliação e informação por parte da sociedade civil, podem ter interferido nos rumos de cada projeto.

Conforme Cavaliere e Maurício (2009) a ampliação do tempo escolar proposta por estas experiências, estão baseadas em argumentos que vão desde as práticas de democráticas, visando uma educação reformadora, até ideais eleitoreiros, com predomínio da preocupação assistencial sobre a pedagógica.

Para Palma Filho (2005) os projetos implementados no Brasil com vista à ampliação do tempo escolar para as escolas públicas brasileiras, foram grandes vitrines políticas, pois à custa de muita propaganda nos meios de comunicação, convenciam a população de que seriam a melhor solução para melhorar a qualidade da educação pública, favorecendo ainda mais, o clientelismo político no país.

Observamos que a partir da década de 1980, houve um retorno das experiências de escolarização em tempo integral, com iniciativas governamentais que ocorreram após um longo período da ditadura militar, quando grupos políticos progressistas, passaram a influir na administração pública estabelecendo novos rumos para as políticas educacionais brasileiras, e, dentre elas, as educacionais (BID, 2010).

Podemos notar que a partir desta mesma década (1980) amplia-se o debate sobre a extensão do tempo diário de escolaridade, seja para suavizar o grau de pobreza de crianças oriundas das classes menos favorecida, seja para melhorar a qualidade e produtividade do ensino oferecido pela escola pública. Nota-se que nos discursos oficiais, a política de ampliação do tempo escolar passa a ser vista como possibilidade de melhoria da qualidade do ensino na escola pública brasileira. 


\title{
3 AMPLIAÇÃO DO TEMPO ESCOLAR, COMO POSSIBILIDADE DE MELHORIA NA QUALIDADE DO ENSINO NO PAÍS
}

O final da década de 1980, e início da década de 1990, foi um período marcado pelo debate sobre a atual Lei de Diretrizes e Bases da Educação Nacional, Lei 9.394, aprovada em 1996. Tal Lei faz referência à escolarização em tempo integral no contexto atual, conforme pode ser observado.

\begin{abstract}
Art. 34 - A jornada escolar no ensino fundamental incluirá pelo menos quatros de trabalho efetivo em sala de aula, sendo progressivamente ampliado o período de permanência na escola.
\end{abstract}

$\S \bigcirc$ ensino fundamental será ministrado progressivamente em tempo integral, a critério dos sistemas de ensino.

At. 87

$\S 5^{\circ}$ Serão conjugados todos os esforços objetivando a progressão das redes escolares públicas urbanas de ensino fundamental para $\circ$ regime de escolas de tempo integral.

Conforme o trecho acima, observamos que a ampliação do tempo

(no sentido de extensão da jornada) nas escolas públicas brasileiras passa a ser efetivamente prevista em Lei a partir da década de 1990, na Lei de Diretrizes e Bases da Educação Nacional (LDB), Lei 9394/1996, e reafirmada no Plano Nacional de Educação (PNE), Lei 10.172/2001 e no atual Plano Nacional de Educação (PNE - Lei no 13.005/14).

\footnotetext{
Devido à ampliação da crise do capitalismo, a partir de 1990, os países imperialistas, por meio de seus organismos multilaterais, como - Banco Mundial e a UNESCO, impuseram aos países semicoloniais, como o Brasil, orientações para que ampliassem a jornada escolar como medida de segurança social nas áreas mais empobrecidas. Observando essas orientações, o Ministério da Educação (MEC) implantou programas de ampliação da jornada escolar na educação básica trazendo para dentro da escola o debate acerca das teorias e práticas da educação integral (SOUZA; ALEPRANDI; TRENTINI, 2016, p. 33).
}

A discussão sobre a educação integral em tempo integral no Brasil se ampliou na segunda metade do século XX, e ganhou espaço nas políticas públicas educacionais mais amplas, com a implantação de programas de tempo integral nas escolas, principalmente, a partir do início da década de 
90. Com investimentos de recursos externos, a política pública educacional passou a elaborar e a executar seus projetos e programas, selados em pactos de enfrentamentos de graves problemas que geram as desigualdades sociais.

É neste contexto que se expande a retórica do colapso do aparelho administrativo-burocrático do setor público (TORRES, 2010). Visando cumprir a agenda política neoliberal, de ajuste educacional, ações passam a ser efetivadas tais como: a privatização e a descentralização, parcerias, extinção de órgão, o mercado livre educacional e as políticas de livre escolha, a avaliação institucional, o controle da qualidade e a eferição da eficácia e da eficiência nas organizações educativas, autonomia e outros, são termos que fizeram parte dos discursos oficiais (LIMA, 1996).

A partir daí se constitui uma cultura, uma ideologia justificadora e explicativa, que marcou os anos 90, com a hegemonia neoliberal vivenciada pelas instituições educacionais (FERREIRA, 2007).

Dentro dessa nova institucionalidade configurada pelo capital, temos já incorporado uma lógica mercantil perversa, sendo induzida por diversos meios e formas, seja através dos meios de comunicação, seja por meio de programas de financiamento, que condicionam as instituições públicas a assumirem a gestão gerencial, o planejamento estratégico, a cultura da avaliação (benchmarking), o incentivo ao individualismo, por meio do empreendorismo, demonstrando que os desafios estão aí para quem quiser e puder se adequar (SANTOS, 2014, p. 464).

Segundo Torres (2010) a partir da década de 90 prevalece a hegemonia da perspectiva integradora na análise da cultura organizacional em diversos contextos educativos, associada à adopção de metodologias de natureza quantitativa e estatísticas, inscreve-se num movimento mais amplo de afirmação das ideologias mais tecnicistas e gestionárias, voltadas para os valores da excelência, eficácia e produtividade.

Os estudos de Jesus e Borges (2015) apontam que desde a década de 1990, as políticas públicas educacionais no Brasil, com a adesão às orientações de organismos internacionais como o Banco Mundial e a 
UNESCO, tenderam a sobrepor as funções da escola o que acentuou a ineficiência dos sistemas educativos para cumprir tal tarefa, evidenciando, sobretudo, sua desvinculação com as necessidades do sistema produtivo.

Diante deste contexto, percebemos que a escola em tempo integral se encaixa dentro dessa política de programas. Embasada em um discurso utópico de que a escola em tempo integral é o tipo mais adequado de instituição escolar capaz de levar o aluno a desenvolver-se integralmente perpassa projetos educacionais voltados para essa temática e para os ideais do Banco Mundial, como afirmam Jesus e Borges $(2015$, p.6).

\begin{abstract}
A influência das agências internacionais como o banco Mundial têm causado à educação escolar consequências direta no que se refere à qualidade no ensino. Nessa perspectiva, o Banco Mundial objetivando melhorar a qualidade do ensino aposta na ampliação do tempo de instrução, estabelecendo uma simples equação entre ampliação do tempo de instrução dos alunos e a qualidade do ensino. Essa visão proporcionou uma ressignificação da escola em tempo integral visando concretizar esta aposta e alcançar a sonhada melhoria da qualidade do ensino.
\end{abstract}

O pacote de reformas elencadas pelo Banco Mundial que tem como estratégia essa ação, não pode ser visto como a melhor alternativa para a melhoria da qualidade do ensino no país, uma vez que, outros fatores estão atrelados nessa tarefa, tais como: os processos pedagógicos, o currículo, a relação escola/comunidade, formação continuada dos professores, melhores condições de trabalho docente e outros. Para Libâneo (2010) os fatores internos são responsáveis pela melhoria do ensino, na medida em que podem proporcionar a aprendizagem do indivíduo.

As demandas e pressões sociais que exigem da escola uma melhor oferta de escolarização básica de uma sociedade urbana provedora de novas necessidades econômicas, culturais e sociais têm apontado a educação integral e a escola de tempo como horizonte de possibilidades de melhoria da oferta e da qualidade de educação básica no Brasil.

O Exemplo disso, são as diversas experiências efetivadas em estados e municípios que contemplam a ampliação da jornada escolar das crianças e adolescentes, como é o caso de experiências recentes em Americana-SP 
(1990); Apucarana-PR (2001); Palmas-TO (2004); Belo Horizonte-MG (2005); Nova Iguaçú-Rj (2006); Santa Catarina-RS (2004), Minas Gerais-MG (2004); Maranhão (2007), Pará (2012) e outras.

Atualmente, observamos a retomada da proposta de escolarização em tempo integral, sendo desenvolvida em todo país, principalmente sobre a administração das esferas estaduais e municipais, muitos idealizam essa política como solução para os graves problemas educacionais. No entanto, muitas propostas vêm sendo efetivadas nos sistemas escolares, de forma improvisada, fazendo usos das mesmas estruturas físicas e utilizando as mesmas técnicas, como se fosse possível desenvolver educação integral numa perspectiva de tempo integral, em espaços escolares planejados para atenderem um quantitativo de aluno em período parcial, além disso, muitos espaços estão sucateados não permitindo que o tempo de permanência das crianças e adolescentes seja ampliado nas escolas públicas do Brasil.

\section{CONSIDERAÇÕES FINAIS}

Notoriamente, ganha destaque no cenário dos debates educacionais um tema recorrente: a tentativa de qualificar a escola pública por meio de organizações escolares em tempo integral. A revisão histórica da (ou das) experiência (s) tem apontado a crença dos defensores da escola em tempo integral nas suas possibilidades qualitativas. Por outro lado, as experiências históricas não tiveram fôlego para sua consolidação enquanto política de Estado, no momento em que demonstram a continuidade e interrupções, ocasionadas pela troca de comandos administrativos, configurando-se como políticas de governos/partidários.

Entendemos que estas experiências materializadas ao longo das últimas décadas no Brasil, tiveram como princípios e fundamentos a ampliação do tempo escolar com vistas a proporcionar às crianças e adolescentes uma educação integral. Entretanto, sofreram influências políticas partidárias, que muitas vezes as desconfiguram de seus focos formativos. O ideal seria que os caminhos tomados por essas políticas públicas educacionais que visam à promoção de uma educação integral 
em tempo integral, fossem direcionados pela sociedade que delas se beneficiam, e não apenas pelas iniciativas de grupos políticos partidários que se favorecem dessas políticas como suporte nas campanhas eleitoras.

As discussões realizadas neste trabalho propiciaram a compreensão de que a ampliação do tempo escolar passou a ser usada nos discursos oficiais como a solução para o enfrentamento aos problemas sociais e da educação, principalmente a partir da década de 1990, quando as políticas públicas educacionais no Brasil passaram a ser conduzidas pelas orientações de organismos internacionais como o Banco Mundial e a UNESCO. No entanto, o pacote de reformas elencadas pelo Banco Mundial que tem como estratégia, essa ação não pode ser vista como a melhor alternativa para a melhoria da qualidade do ensino no país, uma vez que, outros fatores estão atrelados a essa tarefa, tais como: os processos pedagógicos, o currículo, a relação escola/comunidade, formação continuada dos professores, melhores condições de trabalho docente e outros.

Notamos que, tais orientações incumbiram à escola em tempo integral o papel de oferecer aos alunos da escola básica, uma educação capaz de prepará-los para o mercado de trabalho, e ao mesmo tempo, se fundamentam em retóricas enganosas de minimizar as desigualdades sociais e ainda melhorar a qualidade do ensino, uma vez que os alunos passariam mais tempo dentro das instituições escolares.

Diante deste quadro, nos últimos anos observamos que a educação brasileira caminha para o aumento progressivo da jornada escolar (LDB 9394/96 artigos 34 e 87) favorecendo projetos de educação integral. Contudo, a proposta de educação integral em tempo integral, tem acompanhado a educação brasileira em diferentes momentos e a partir de diferentes propostas e experiências.

De fato, se for feita uma aposta na escola em tempo integral, que seja feita no modelo de escola, a partir de um projeto político pedagógico, consolidando sua centralidade enquanto instituição formadora e, que esse projeto possa ser construído coletivamente, buscando no poder público, verbas necessárias a sua consecução, sem interferências externas. 
Justamente por esta razão, a escola em tempo integral precisa deixar de ser experiência para ser uma política educacional, amparada por uma legislação regulamentadora e desafiada a responder pela concretização do seu maior objetivo histórico: a qualidade da escola pública.

Acreditamos que essa temática não se esgota aqui, devido ao papel que vem assumindo na agenda pública dos governos e por ser um tipo de organização escolar ainda em construção, uma vez que não conseguiu se firmar como uma escola que busca dar as mesmas oportunidades educativas para todos, mas apenas serve como uma instituição que utiliza a ampliação do tempo escolar para oferecer o mínimo para uma minoria, o que deveria ser o contrário.

\section{REFERÊNCIAS}

BOMENY, H. A escola do Brasil de Darcy Ribeiro. Em Aberto, Brasília, v.22, n. 80, p. 1-165, abril, 2009.

BRASIL. Instituto Nacional de Estudos e Pesquisas Educacionais Anísio Teixeira. Brasília, 2015.

BRASIL. Lei $n^{\circ}$ 9.394, de 20 de dezembro de 1996: dispõe sobre as diretrizes e bases da educação nacional. Diário Oficial da União, Brasília, 23 dez. 1996.

BRASIL. Lei $\mathbf{n}^{\circ}$. 10.172, de 09 de janeiro de 2001. Aprova o Plano Nacional de Educação e dá outras providências. Presidência da República, Casa Civil, Subchefia para Assuntos Jurídicos. Disponível em: <http://www.planalto.gov.br/ccivil_03/leis/leis_2001//10172.htm>. Acesso em: 16 ago. 2015.

BRASIL. Lei $n^{\circ} 13.005 / 14$. Aprova o Plano Nacional de Educação e dá outras providências. Diário Oficial da União, Brasília, DF, 26 jun. 2014.

CAVAlieRE, A. M. Tempo de escola e qualidade na educação pública. Educação \& Sociedade. Número especial - Educação escolar: os desafios da qualidade, Campinas, v. 28, n. 100, p. 1015-1035, 2007.

CAVALIERE, A. M. Escola de tempo integral versus alunos em tempo integral. In: MAURíCIO, L. V. (Org.). Educação integral e tempo integral. Brasília: Em Aberto/ Instituto Nacional de Educação e Pesquisas Educacionais Anísio Teixeira. V.1, n.1, 2009.

CAVAliere, A. M. Escola pública de tempo integral no Brasil. Educ. Soc. Campinas, v. 35, nº 129, p. 1205-1222, out. dez., 2014. 
CHIOZZINI, D. F; SANTOS, I. M. dos. Os Cantores, a Viagem à Lua e a Favela uma experiência de ensino de língua portuguesa nos ginásios vocacionais durante a ditadura militar. III Seminário Internacional de História do Tempo Presente. UDESC- Florianópolis- SC, 2017. Anais... 2017.

COELHO, L. M. C. Escola pública de horário integral: um tempo (fundamental) para $\mathrm{O}$ ensino fundamental, 2007. Disponível em www.educacaoonline.pro.br. Acesso em 11/10/2010.

DIB, M. A. B. O programa escola de tempo integral na região de Assis: implicações para a qualidade de ensino. 2010. 207 f. Tese (Doutorado em Educação) - FFC/UNESP, Marília.

ÉBOLE, T. Uma experiência de educação em tempo integral. Centro Educacional Carneiro Ribeiro. MEC - INEP - Bahia, 1969. Disponível em http://www.dominiopublico.gov.br/download/texto/me001840.pdf

FERREIRA. C. M. F. S. Escola de Tempo integral: possível solução ou mito na busca da qualidade? 2007, 149f. Dissertação de Mestrado. Universidade Estadual Paulista, 2007.

FERRETTI, C. J. et al. "Escola pública em tempo integral: O Profic na rede estadual em São Paulo". Cadernos de Pesquisa. São Paulo: n 76, fev. 1991, pp. 5-17.

FREITAS, C. R.; GALTER, M. I. Reflexões sobre a educação em Tempo Integral no decorrer do século XXI. Revista da Educação. Vol. 2 n 3 jan./jun. 2007 p.123-138. Disponível em: http://e-revista.unioeste.br. Acesso: 10/03/2009.

GADOTTI, M. Educação Integral no Brasil: inovações em processo. São Paulo: Editora e livraria Instituto Paulo Freire, 2009.

GIOVANNI, G.; SOUZA, A.N. Crianças na escola? Programa de Formação Integral da Criança. Educação \& Sociedade, ano XX, n.67, 1999. Disponível em: http://www.scielo.br. Acesso em: 10/01/2010.

JESUS, A. C de; BORGES, W. S.C. A ampliação do tempo escolar nas escolas públicas. Texto apresentado no $2^{\circ}$ Encontro de licenciaturas do sudoeste goiano. 21 a 23/05/2015. UFG/Regional Jataí.

LIMA, L. O paradigma da educação contábil: políticas educativas e perspectivas gerencialistas na educação em Portugal. ANPED: Revista Brasileira de Educação, 1996.

MENEZES, E. T. de; SANTOS, T. H. dos. Verbete CIACs (Centros Integrados de Atendimento à Criança). Dicionário Interativo da Educação Brasileira Educabrasil. São Paulo: Midiamix, 2001. Disponível em: 
<http://www.educabrasil.com.br/ciacs-centros-integrados-de-atendimentoa-crianca/>. Acesso em: 16 de dez. 2017.

NUNES, C. Centro educacional Carneiro Ribeiro: concepções e realização de uma experiência de educação integral no Brasil. Em Aberto, Brasília, v. 22, n. 80, p. 1-165, abril, 2009.

PEREIRA, E. W.; ROCHA, L. M. F. Escola Parque de Brasília: uma experiência de educação integral. In: PEREIRA, E. W.; COUTINHO, L. M.; RODRIGUES, M. A.; HENRIQUES, C. M. N.; SOUZA, F. H. de M.; ROCHA, L. M. da F. (Org.). Nas asas de Brasília memórias de uma utopia educativa (1956-1964). Brasília: Editora UnB, 2011, v, p. 9-375.

RIBEIRO, M. R. A Relação entre Currículo e Educação Integral em Tempo Integral: um estudo a partir da configuração curricular do programa mais educação. Tese (doutorado em educação) - PPGED, 2017.

SANTOS, T. A crise atual do capitalismo na formação do estado contemporâneo e gestão da educação. Revista de Políticas Públicas. ISSN 2178-2865 (online) ISSN 0104-8740 (impresso). Volume 18, 2014.

SOUZA, M.; ALEPRANDI, R.; TRENTINI, S. As Concepções Filosóficas e Pedagógicas de Educação Integral no Brasil e as Políticas Educacionais. In: COSTA, S. A.; COLARES, M. L. I. S. (Org). Educação Integral: concepções e práticas a luz dos condicionantes singulares e universais - Curitiba: CRV, 2016.

TAMBERLINI. A. R. M. B. Os ginásios vocacionais: a dimensão política de um projeto pedagógico transformador. São Paulo: Annablume, 2001.

TORRES, L. Cultura, Gerencialismo e Democracia na Escola Pública. In: Praxis educativa, v.6, n.9,2010. Dossiê Temático - Disponível: http://periodicos.vesb.br/index.php/praxis/article/viewFile/425/452.

Recebido em: Abril de 2018 Aprovado em: Julho de 2018 